\title{
MODELING OF THE PRECIPITATION INDUCED FLASH FLOOD IN SARPANG, BHUTAN USING HEC-RAS
}

\author{
Jigme Tenzin and Aparna S. Bhaskar \\ Department of Civil Engineering, SRM University, Kattankulathur-603203, \\ Chennai (Tamil Nadu) India \\ *E-mail : jigmetenzinn@gmail.com
}

\begin{abstract}
Flood is define as a natural disaster that causes loss of life and property damages. Flash flood is an overflow of water that submerge lands and properties affecting lives and habitats all around the world due to climate change and heavy rainfalls. It is impossible to avoid risk or prevent their occurrence but we can reduce their effects by various engineering techniques. Incessant monsoon rains in the month of July 2016, triggered flash floods in several southern districts of Bhutan including Sarpang town affecting hundreds of people. The town was also wiped out after an overnight flash flood in 1996 and several minor flash flood kept on occurring particularly during monsoon. Hence, the present study aims to model the flash flood with respect to rainfall at Sarpang, Bhutan and to understand the suitability of methods in mountain terrain. Modelling was done by integrating ArcGIS and HEC-RAS modelling software. SRTM DEM and Landsat 8 OLI satellite image were used as base data. Meteorological data from Department of Hydro Met Services, Bhutan has been used to calculate average discharge of the river outlet. The model was validated with the recent flash flood event and also study shows that the methods and procedures adopted in this paper are suitable for carrying out similar kind of studies in mountain terrain like Sarpang where flash floods are very frequent and most common.
\end{abstract}

Keywords: Flash flood, Modelling, Roughness Coefficient, HEC-RAS, LULC, SRTM DEM

(C) RASĀYAN. All rights reserved

\section{INTRODUCTION}

A flood is an overflow of water that submerges land, cause damages to agricultural lands, urban areas, and result in loss of lives ${ }^{1}$. Floods also can be explained as excess flows exceeding the transporting capacity of river channel, lakes, ponds, reservoirs, drainage system, dam and any other water bodies, whereby water inundates outside water bodies areas ${ }^{2}$. Flash flood is an integrated effect of high intensity rainfall, unexpected breach of lakes, collapse of check dams and very steep topography ${ }^{3}$. It gives impact to human lives causing severe economic loss due to damages. It is impossible to avoid risks or prevent their occurrence, however it is credible to work on the reduction of their effects ${ }^{4}$.

International researchers with Asian Disaster Reduction Centre (ADRC) in 2015 stated that the most recent climate change effect disaster took place in Bhutan (2009 Cyclone Aila precipitated floods), taking 12 lives and causing losses of more than $\mathrm{Nu} .700$ million $^{5}$. Also stated that flash flood is one of the most common and devastating natural disaster occurs in Bhutan during monsoon (June, July and August) 5 .

Incessant monsoon rains, since 19 July, 2016 triggered flash floods in several southern districts of Bhutan. The heavy rainfall caused the Sarpang River to overflow and flooded Sarpang town on 21 July affecting 63 families $^{6}$. Portion of Tsirang Sarpang Highway has also been washed away (Office of the Resident Coordinator Situation Report, 2016) ${ }^{6}$. The flood water completely destroyed recently transplanted paddy fields of some 30 households. Sarpang town has faced number of such destruction due to flash flood. The town was also wiped out after an overnight flood in 1996 (Kuensel, 22 July 2016) ${ }^{7}$. Flash flood in Sarpang, especially in the downstream part is a combined effect of rainfall in the highlands that goes through tributaries of the main stream. Some literatures suggest that the frequency and magnitude of river flood might increase due to climate change. Flash flood is a big concern in Sarpang due to human welfare losses and crop damages which stipulates indispensability of flood inundation 
RASĀYAN J. Chem.

Vol. 10 | No. 2 |399 - 406 | April - June | 2017

mapping and hazard assessment. There is a need for flood regulation, timely forecasting and hazard extent mapping in the Sarpang Area. The objectives of this study is to model the precipitation induced flash flood and understand the suitability of the methods and procedures adopted for carrying out similar kind of studies in future.

\section{Study Area}

The study area watershed is located between $26.71^{\circ} \mathrm{N}$ and $27.23^{\circ} \mathrm{N}$ latitudes and $90.01^{\circ} \mathrm{E}$ and $90.83^{\circ} \mathrm{E}$ longitudes. It covers an area of $142.89 \mathrm{~km}^{2}$ and serves as home to about 3000 inhabitants (NSB, 2005). The total length of the main stream is about $18 \mathrm{~km}$ and it is the principal stream of drainage basin covering major parts of Hiley Geog and some part of Shompangkha region. Land use landcover is mainly dominated by Forest followed by agriculture land and settlement. The main location covers the Sarpang Town with major affected Market Area. Main cash crop grown are rice and ginger. The communities also depend on livestock rearing for income generation.
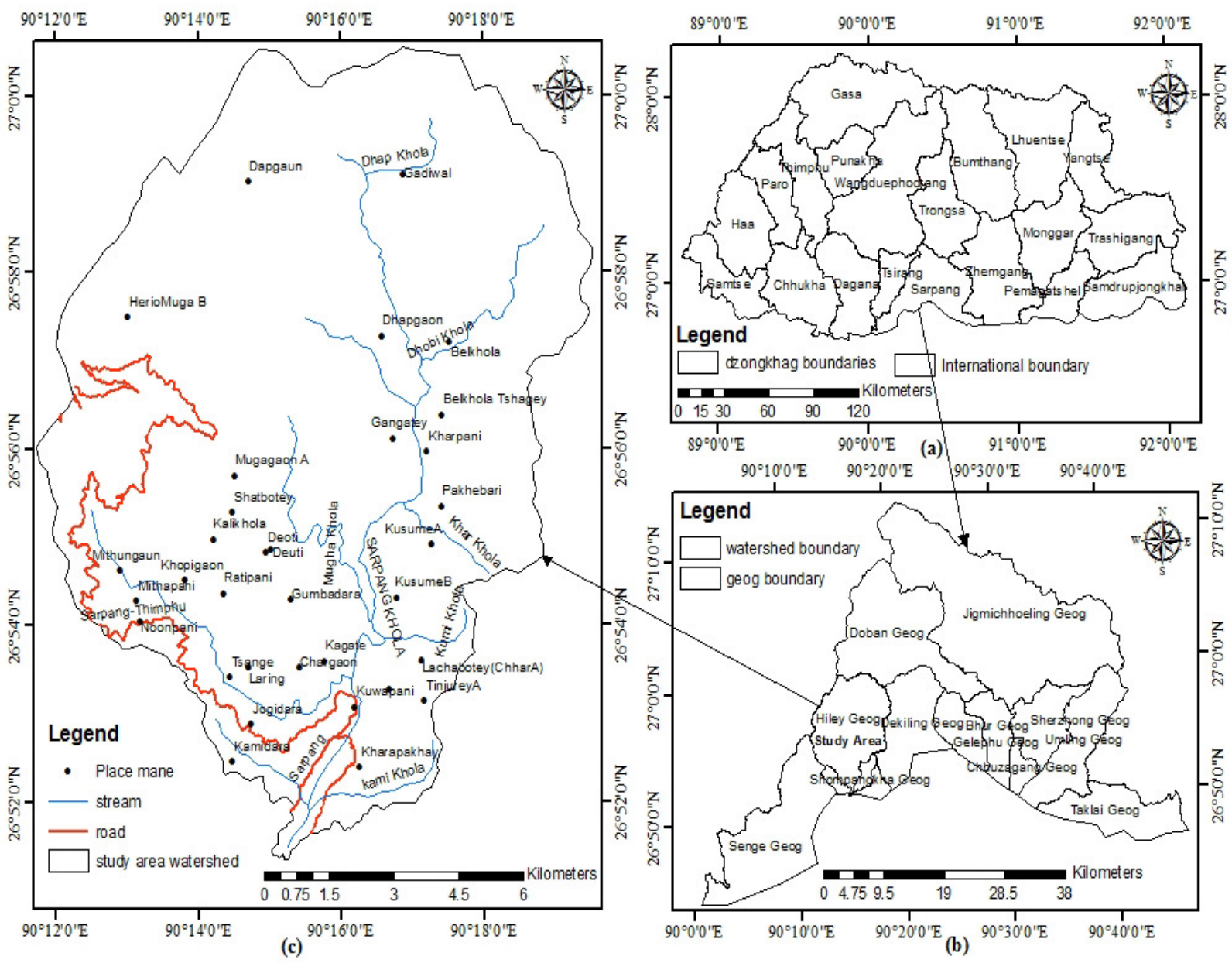

Fig.-1: Study area: (a) Dzongkhag map of Bhutan, (b) Geog map of Sarpang and (c) Study area watershed

The sites fall within tropical to subtropical type of climatic zone with altitudes ranging from about $170 \mathrm{~m}$ to 4200 metres above mean sea level. The sites vary in topography from nearly flat to steep mountainous slopes. Although, sheltered from the full force of the monsoon by the Meghalaya hills in India, southern Bhutan receives heavy intense orographic rainfall, with annual mean of 2.5-5 m (Land Use Planning Project, 1994) and mean annual temperature of 16.7 degree Celsius (NSB, 2013). Study area watershed with base map is shown in Figure-1. 


\section{Materials used}

\section{EXPERIMENTAL}

SRTM DEM (Shuttle Radar Topographic Mission Digital Elevation Model) from USGS (1arc second taken on $23^{\text {rd }}$ September, 2014) has been used as main input data and Landsat 8 OLI images (30m resolution taken on $27^{\text {th }}$ April, 2016) for landuse landcover classification. Ancillary data like rainfall from Meteorology Division, Department of Hydro Met Services (DHMS), Ministry of Economic Affairs (MoEA), Bhutan, Topographic map from National Land Commission Secretariat (NLCS) and other data from National Statistics Bureau of Bhutan (NSB) were used.

ArcGIS 9.2 was used for mapping and spatial analysis. ArcGIS 9.2 extension HEC-GeoRAS 9.2 and HEC-RAS 5.0.1 (Hydrologic Engineering Centre-River Analysis System) from US Army Corps of Engineers were used for data processing and analysis.

\section{Methodology}

Overall flowchart of the methodology adopted for this study is as shown in the Figure 2. SRTM DEM was used as base data for overall methodology and processing to generate TIN (Triangulated Irregular Network). Watershed area was delineated using Spatial Analysis Hydrology Tools in ArcGIS by considering the stream outlet at downstream end as pour point.

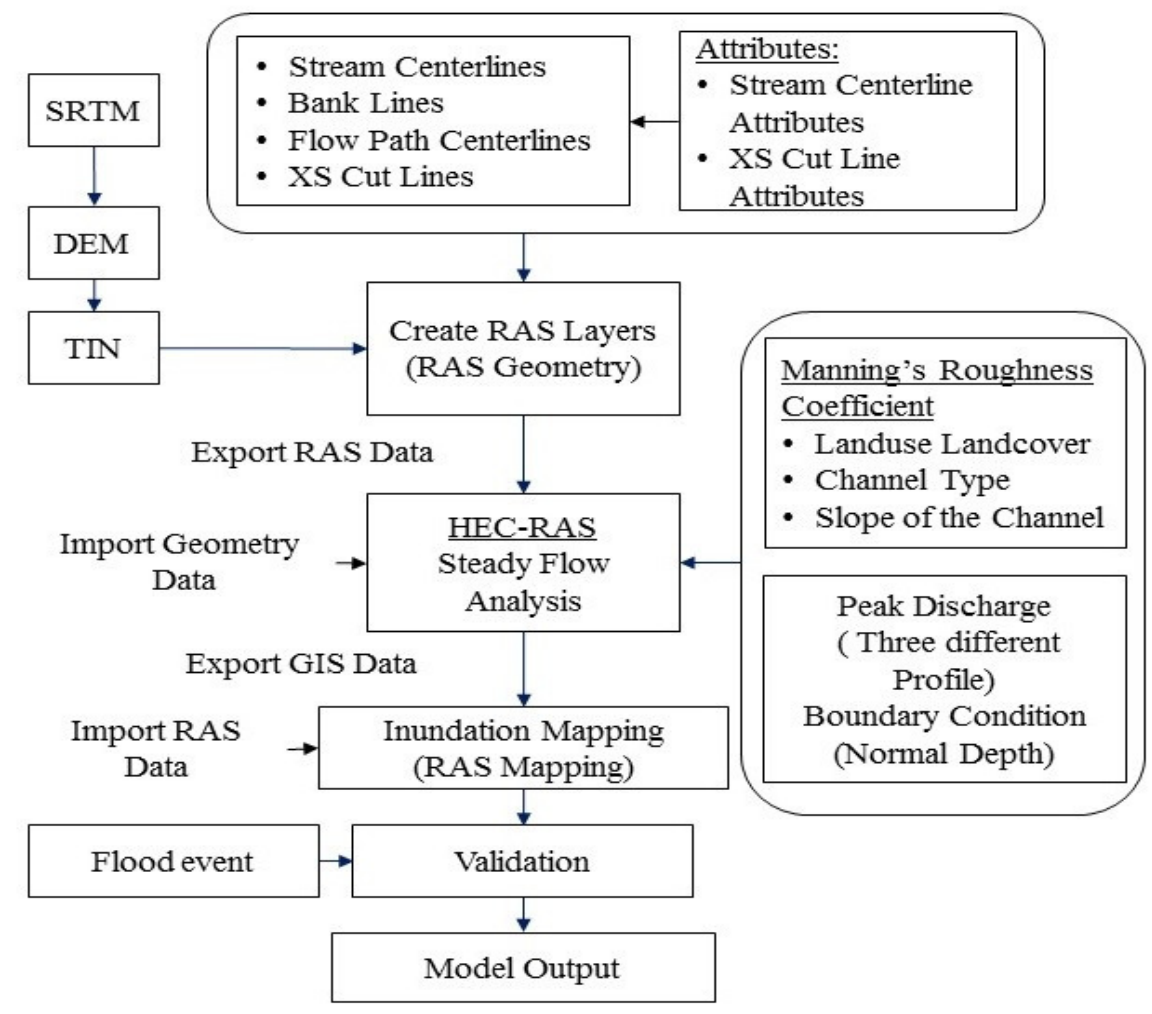

Fig.-1: Methodology

Chakrabarty and Mandal (2015) did the analysis of various hydraulic model to detect flash flood probability using HEC-RAS and combined used of HEC-HMS and HEC-RAS models in GIS in order to simulate flood which their results indicates the effectiveness of HEC-RAS models ${ }^{3}$. Hashemyan et al. (2015) have also proved the effectiveness of HEC-RAS models ${ }^{8}$. Therefore, this study deploy HEC-RAS software assist by interfacing ArcGIS extension; HEC-GeoRAS, and ArcGIS to analyze its effectiveness in high mountain terrain like Sarpang. Reba et al. (2015) assume the flow as steady and uniform flow characteristics while modelling to compute inundation in HEC-RAS by relating to an open channel ${ }^{9}$. The 
authors used an integrated spatial technology of Geographical Information System (GIS) and the HECRAS hydraulic model for flood inundation mapping with good accuracy output indicating the effectiveness of HEC-RAS model and ArcGIS. The stream in this study was considered steady flow as it is an open channel flow. The studies on Effect of land use based surface roughness on hydrologic model output says for large watershed areas, modelers typically use land use land cover datasets to assign Manning's $n$ values based on the use or cover class 9. Their results also suggest that the use of (National Land Cover Dataset) NLCD-defined Manning's n values is tolerable for medium to large watersheds. Therefore, flood model was generated by incorporating Manning's n values defined by types of channel, slope and landuse landcover of the watershed in this study. It was validated using the information acquired from flash flood historic event of recent past.

\section{RAS Geometric Data Creation}

\section{RESULTS AND DISCUSSION}

TIN was generated using 3D Analyst Tools in ArcGIS by using DEM as an input data. RAS geometric data such as stream centerlines, bank lines, flow path lines and XS cut lines were created using TIN as base layer data in HEC-GeoRAS and delineated by enabling Editor tool in ArcGIS. River reach name and flow path name were also assigned. Finally, stream centerline attributes and XS cut lines attributes were

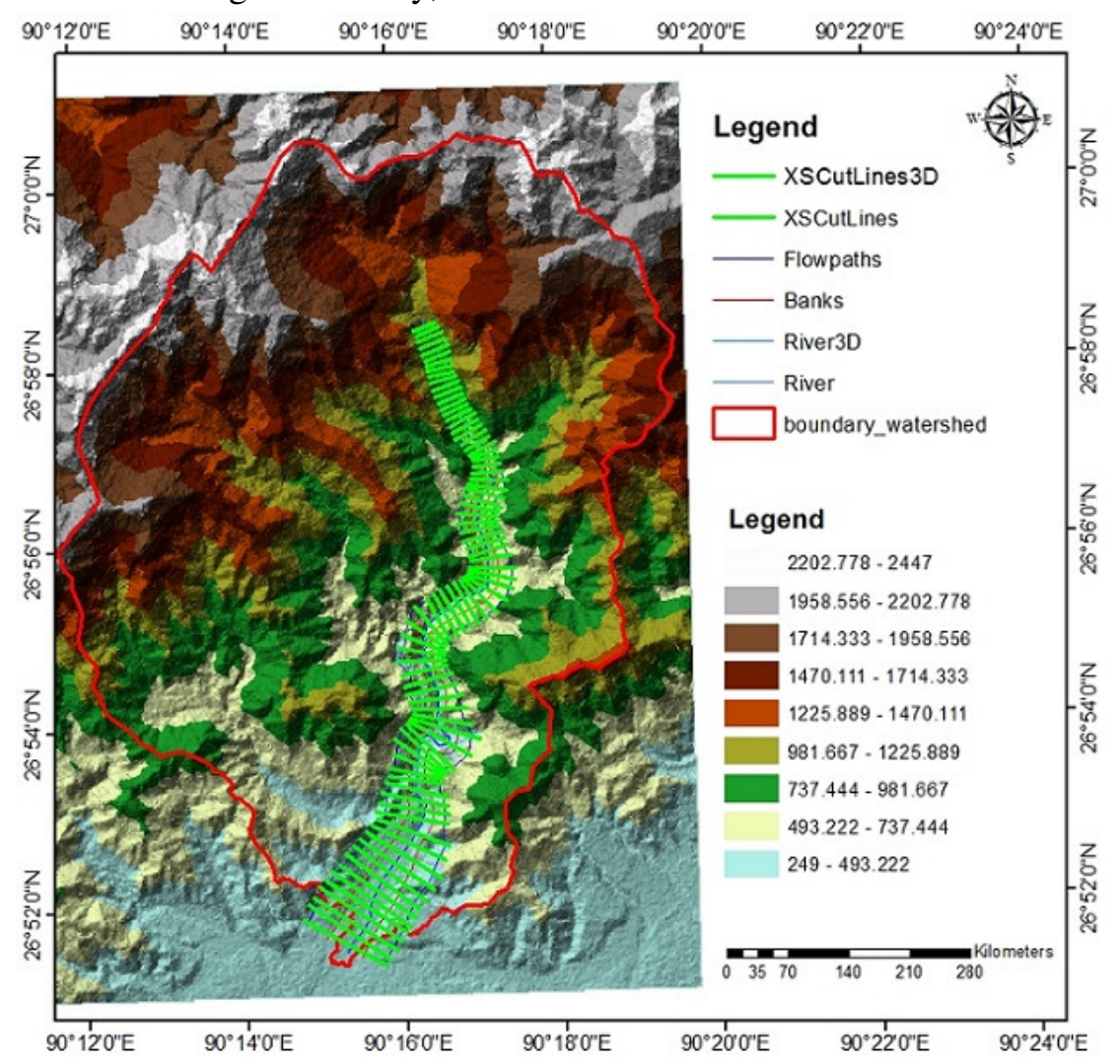

Fig.-3: Geometric Data

also generated. Geometric data thus created was exported as RAS data to be used in HEC-RAS for modelling. It is shown in Figure-3.

\section{Manning's Roughness Coefficient (n value)}

Manning's $n$ values were assigned primarily based on Landuse Landcover with reference to manning's $n$ values adopted for NLCD map ${ }^{10}$. Manning's n for agriculture and overbank areas (Jeff et al. 2006, USGS) and channel type and slope of the channel (McCuen, 2004) were used ${ }^{16}$. Considering the natural earth 
bottom, rubble side channel type and landuse landcover map generated from Landsat OLI image, $\mathrm{n}$ values for study area were assigned and is shown in Table-1.

\section{Peak Discharge}

Peak discharge was assigned from calculated average peak discharge value of 21 years rainfall data. Average daily rainfall data (1996-2016) of Sarpang rain gauge station were collected from DHMS, Bhutan and peak discharge was calculated by Kinematic Wave Parameter (KWP) for Flow Velocity and Discharge Estimation method (Rodriguez-Iturbe et al. 1982) shown in equation (1) ${ }^{11}$. Average slope of channel as 0.4 and channel outlet cross section of $600 \mathrm{~m}^{2}$ were calculated from stream profile and stream cross section respectively which were generated in HEC-RAS software.

Table-1: Manning's n values

\begin{tabular}{l|c}
\hline \multicolumn{1}{c|}{ LULC/Channel Type } & $\mathrm{n}$ values \\
\hline Barren land & 0.0113 \\
\hline Deciduous forest & 0.36 \\
\hline Agriculture land & 0.35 \\
\hline Earth bottom and rubble side & 0.30 \\
\hline
\end{tabular}

Discharge $(\mathrm{Q}=$ d.B.v) $(\mathrm{m} 3 / \mathrm{s})$

Where d.B $=$ Cross sectional area $\left(\mathrm{m}^{2}\right)$

$$
\begin{aligned}
& \mathrm{V}_{\Omega}=0.665 \alpha_{\Omega}{ }^{0.6}\left(\mathrm{i}_{\mathrm{r}} \mathrm{A}\right)^{0.4} \\
& \alpha_{\Omega}=\mathrm{S}_{\Omega}{ }^{0.5} / \mathrm{nB}^{2 / 3}
\end{aligned}
$$

Calculated peak discharge ranges from 700 cumecs to 1000 cumecs. Therefore, peak discharge value of 700, 800, 900 and 1000 cumecs were assigned for analysis profile respectively at four different station along the stream towards downstream reach.

\section{Steady flow analysis}

Steady flow analysis was done in HEC-RAS software based on open flow channel and sub-critical flow regime. Flow cross section, flow profile and 3D cross section with depth of water were generated. The Sarpang Khola stream geometry is shown in Figure 4 and contract cross sections at four different stations with water surface (WS) and energy gradient (EG) is shown in Figure 5. The profile of the stream plotted is shown in Figure-6.

\section{Inundation Mapping}

After steady flow analysis being done in HEC-RAS, GIS data was exported and imported into ArcGIS for inundation analysis using RAS Mapping. Imported GIS data need to be converted from SDF format into XML format. Inundation for profile with flood extend was generated and mapped as shown in Figure 7. It was overlaid upon base map to validate with the historic event of flash flood during July 2016.

\section{CONCLUSION}

Bhutan has experience several flash floods during monsoon especially in the southern foothills. It has causes several damages to agriculture land, settlements etc. affecting the livelihood of habitants. The main cause of such flash flood is high intensity rainfall.

This study was carried out at Sarpang watershed with DEM as base data to generate TIN which was further used for analysis in HEC-Geo RAS and HEC-RAS. The advantages of using SRTM DEM are; freely available, helps in generating useful geomorphological feature data of the study area such as slopes and altitudes, helps in delineating the rivers and streams by using hydrology tools and in creating geometrical data of the study area such as stream centerline, flow path, bank line and cross sections by 
RASĀYAN J. Chem.

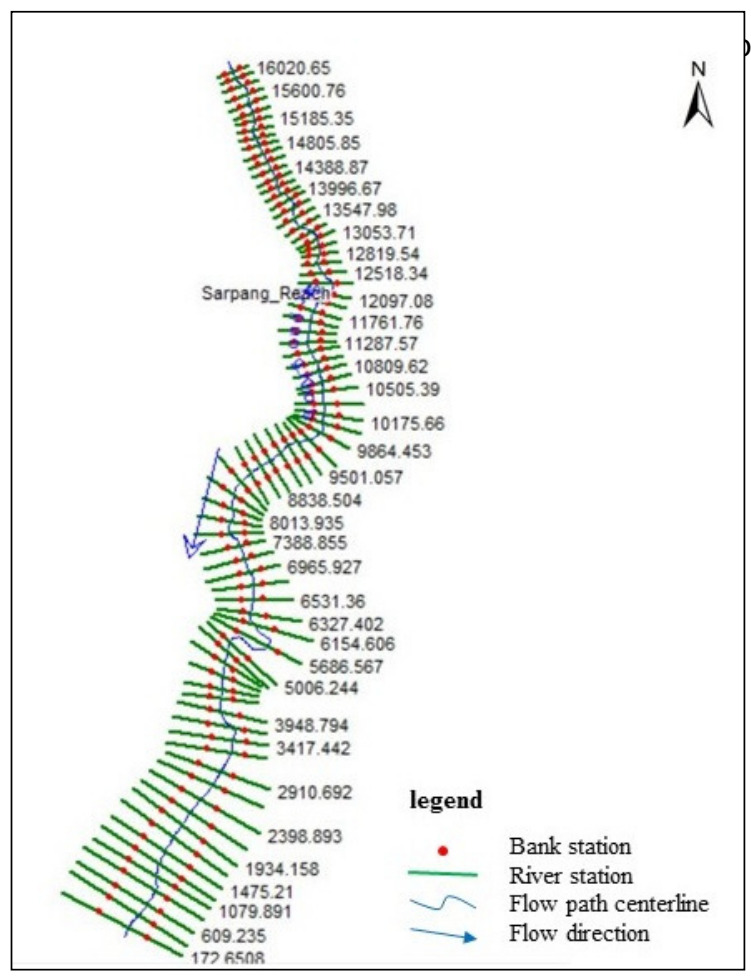

2 |399 - 406 | April - June | 2017

Fig.-4: Stream geometry

converting DEM into TIN in ArcGIS. The only demerits could be because of its availability in low resolution.

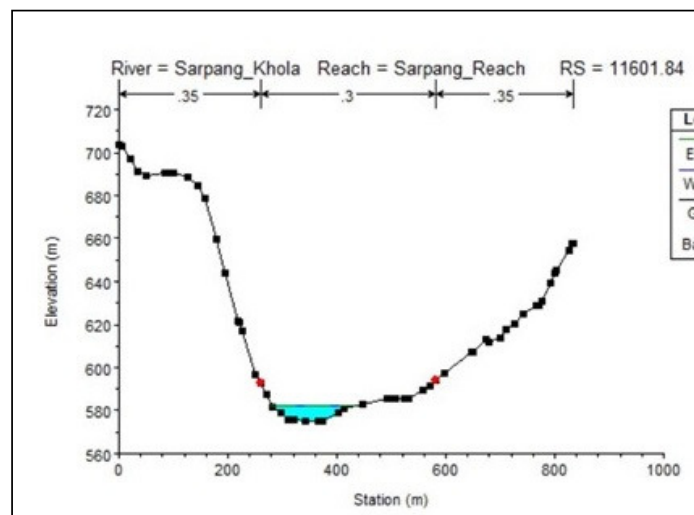

(a)

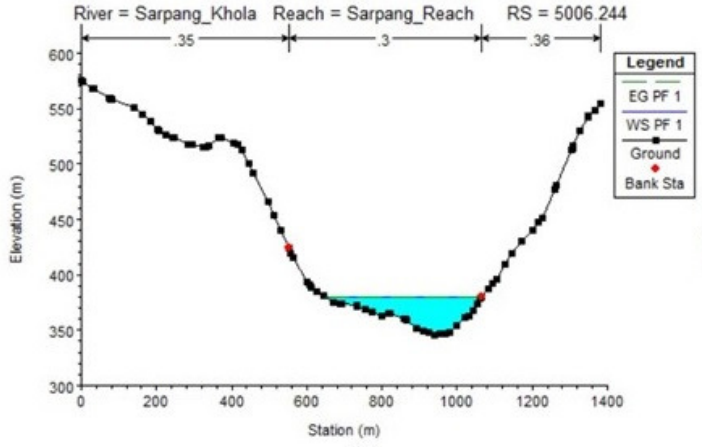

(c)

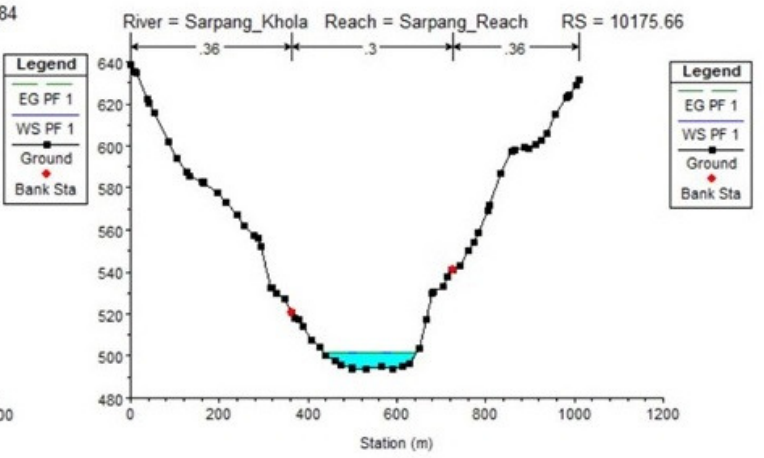

(b)

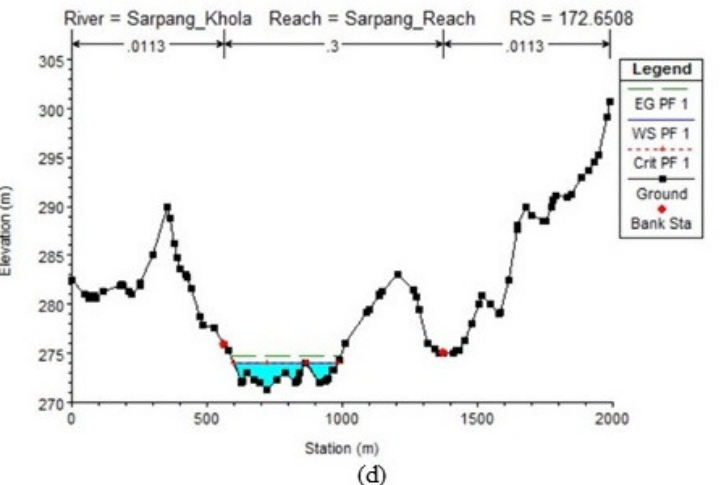

(d)

Fig.-5: Stream cross section: (a) first station, (b) second station, (c) third station and (d) fourth station 
RASĀYAN J. Chem.

Vol. 10 | No. 2 |399 - 406 | April - June | 2017

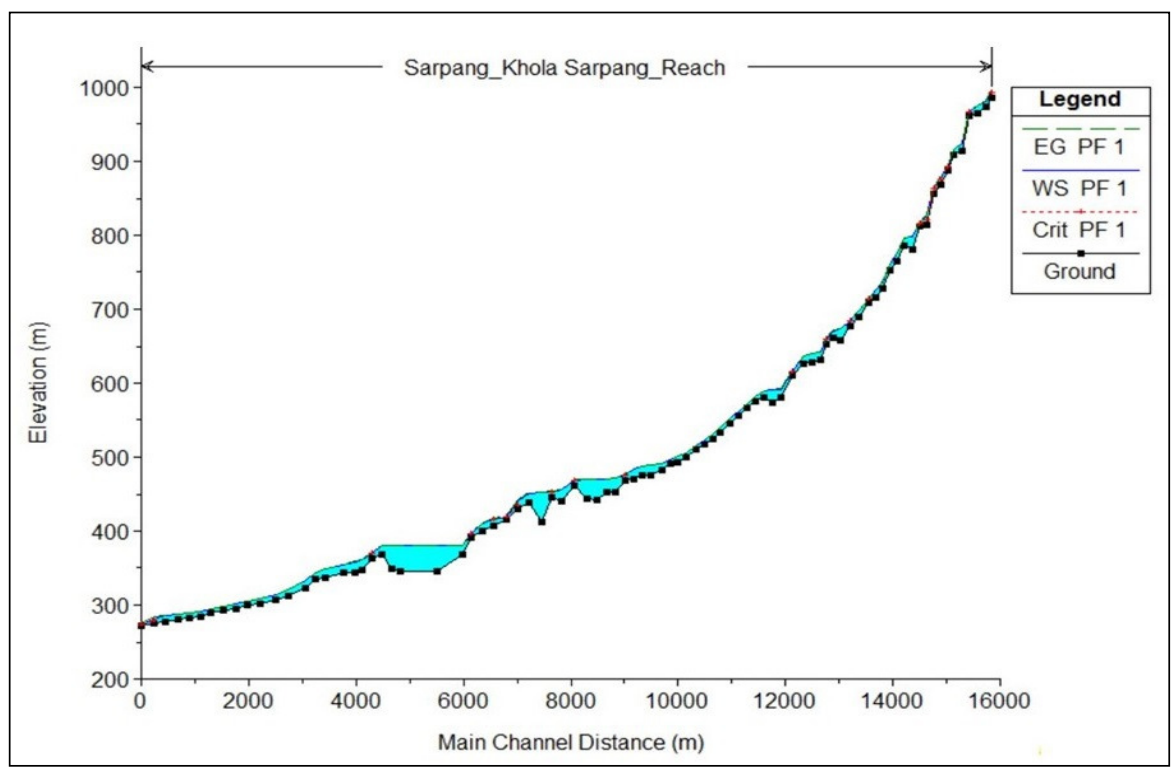

Fig.-6: Stream profile

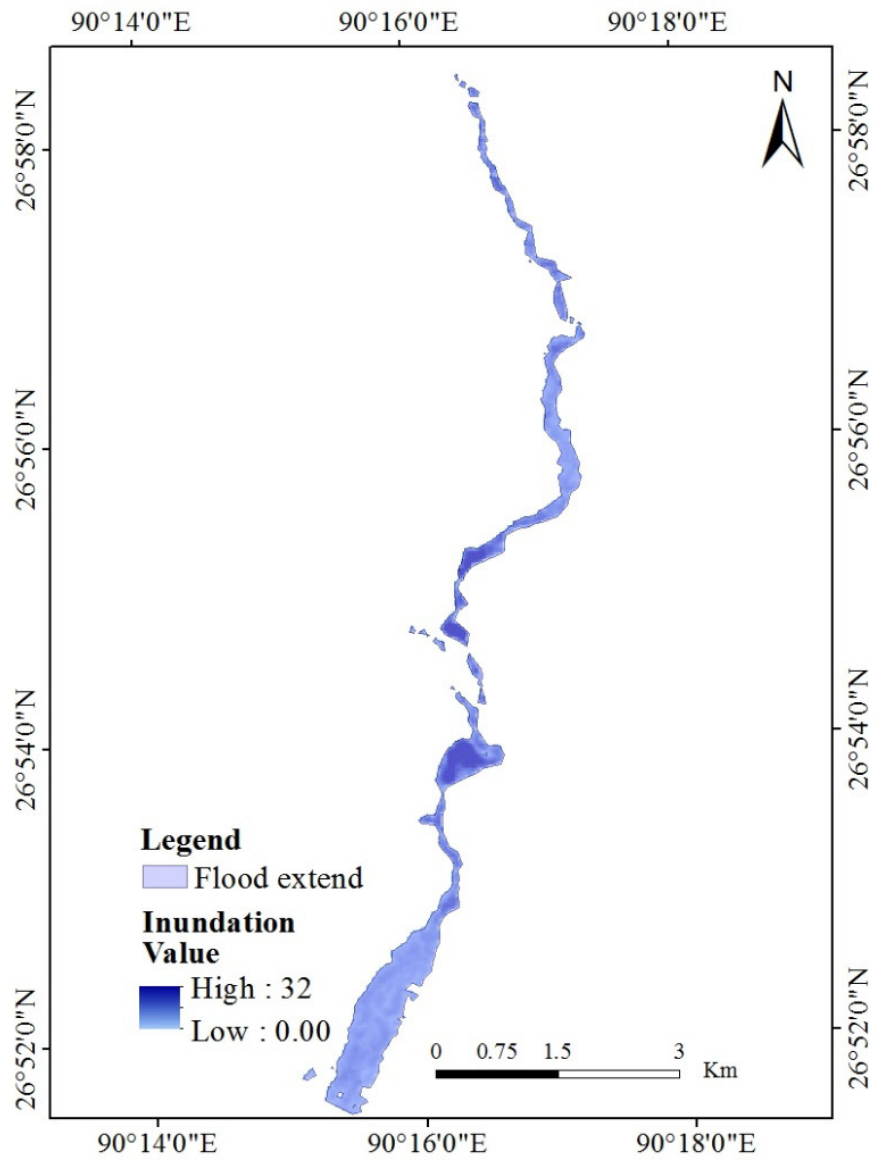

Fig.-7: Inundation and flood extend map

Manning's coefficient values obtained based on land use land cover and stream characteristics were assigned to run the model. Model was run for single stream profile with different discharge rate at four different river station towards downstream as 700, 800, 900 and 1000 cumecs. Peak discharge were 
considered from the average peak discharge calculated by Kinematic Wave Parameter (KWP) for Flow Velocity and Discharge Estimation method (Rodriguez-Iturbe et al. 1982 using daily average rainfall intensity of 21 years (1996-2016) rainfall data collected from Sarpang rain gauge station. Steady flow analysis generates water surface level and successively inundation and flood extend was mapped in ArcGIS with RAS Mapping. Observations made from water surface level at cross sections and overlaying of Inundation and flood extend map with base map and LULC map indicates that the water extends up to $200 \mathrm{~m}$ to $300 \mathrm{~m}$ on both side of the stream centerline with an average depth of $3 \mathrm{~m}$ at downstream which approximately extends over flooded area by recent flood event, thereby validating the model. Therefore, this study also shows that the modeling method adopted can be used for mountain terrain and use of higher resolution DEM (Lidar/World DEM) instead of SRTM DEM enable us to incorporate and include even the smallest engineering structural available within study area like the embankments and walls which ensures higher accuracy output.

\section{ACKNOWLEDGEMENT}

The authors would like to extend our sincere gratitude to Royal Civil Service Commission (RCSC) Bhutan and Government of India (GoI) for funding in studies. We acknowledge Department of Hydro Met Service (DHMS), Bhutan and other organizations for providing with necessary data.

\section{REFERENCES}

1. Y.C.E. Yang, P.A. Ray, C.M. Brown, A.F. Khalil and W.H. Yu, Nat Hazards, 27, 2773(2015)

2. Y.S. Getahun and S.L. Gebre, Journal of Civil and Environmental Engineering, 5(4), 179 (2015)

3. A. Chakrabarty and S. Mandal, In Proceedings of ICDEM 2015: 18th international Conference on Disaster and Emergency Management (2015)

4. I. Eikhrachy, The Egyptian Journal of Remote Sensing and Space Sciences, 18, 261(2015)

5. Country Report; Bhutan Disaster Management, Asian Disaster Reduction Center (2015)

6. Office of the Resident Coordinator Bhutan, Bhutan: Flash Flood - Office of the Resident Coordinator Situation Report No. 2 (2016)

7. N. Pokhrel, (2016, July 22).,Kuensel, Retrieved from kuenselonline: http://www.kuenselonline.com/flood-destroys-sarpang-town/

8. F. Hashemyan, M.R. Khaleghi and M. Kamyar, Research Journal of Recent Sciences, 4(8), 122 (2015)

9. M.N. Md Reba, M.K.A. Halim and N.H. Roslan, In Proceedings of ACRS 2015 - 36th Asian Conference on Remote Sensing: Fostering Resilient Growth in Asia, Asian Association on Remote Sensing. Quezon City, Metro Manila, Philippines: Asian Association on Remote Sensing (2015)

10. J.K. Alfred, J.B. Steven, and N.Mc.P. Timothy, Journal of Spatial Hydrology, 9, 51(2009)

11. S. Roy and B. Mistri, Geography Journal, 2013 (2013), Article ID 214140

12. A. Bansode and K.A. Patil, International Journal of Scientific \& Engineering Research, 5(7), 1283(2014)

13. C.G. Patel and P.J. Gundaliya, Open Journal of Modern Hydrology, 6, 34(2016)

14. R. Harahap, Z. Nasution, A. Rauf and H. Mawengkang, International Research Journal of Engineering and Technology (IRJET), 2(7), 621(2015)

15. S. Kute, S. Kakad, V. Bhoye and A. Walunj, International Journal of Research in Engineering and Technology, 3(9), 81(2014)

16. U.S. Geological Survey Scientific Investigations Report, Selection of Manning's Roughness Coefficient for Natural and Constructed Vegetated and Non-Vegetated Channels, and Vegetation Maintenance Plan Guidelines for Vegetated Channels in Central Arizona (2006)

17. V. Demir and O. Kisi, Advances in Meteorology, 2016 (2016)

[RJC-1648/2017] 